Editorial

\title{
Built Environment, Ethics and Everyday Life
}

\author{
Mattias Kärrholm * and Sandra Kopljar \\ Department of Architecture and Built Environment, Lund University, 22100 Lund, Sweden; \\ E-Mails: mattias.karrholm@arkitektur.Ith.se (M.K.), sandra.kopljar@arkitektur.lth.se (S.K.) \\ * Corresponding author
}

Submitted: 20 October 2020 | Published: 12 November 2020

\begin{abstract}
In the wake of global crises concerning, for example, inequalities, migration, pandemics, and the environment, ethical concerns have come to the fore. In this thematic issue, we are especially interested in the role that the planning, design, and materialities of the built environment can take in relation to ethics, and we present four different openings or themes into urban ethics that we also think are worthy of further interrogation. First of all, we suggest that new ethics evolve around new materialities, i.e., urban development and new design solutions are always accompanied by new ethical issues that we need to tackle. Secondly, we highlight different aspects involved in the design and ethics of community building. Thirdly, we address the issue of sustainable planning by pointing to some its shortcomings, and especially the need to addressing ethical concerns in a more coherent way. Finally, we point to the need to further investigate communication, translation, and influence in participatory design processes. Taken together, we hope that this issue-by highlighting these themes in a series of different articles-can inspire further studies into the much needed field of investigation that is urban ethics.
\end{abstract}

\section{Keywords}

built environment; climate ethics; everyday life; urban design; urban ethics; urban planning

\section{Issue}

This editorial is part of the issue "Built Environment, Ethics and Everyday Life" edited by Mattias Kärrholm (Lund University, Sweden) and Sandra Kopljar (Lund University, Sweden).

(C) 2020 by the authors; licensee Cogitatio (Lisbon, Portugal). This article is licensed under a Creative Commons Attribution 4.0 International License (CC BY).

\section{Introduction}

In old academic culture and in the academic publications of the 17th and early 18th centuries, theology and philosophy were the dominant subjects, and within philosophy there was probably no topic more popular than ethics. Slowly, other disciplines such as the natural sciences, medicine, and the social sciences took over, and ethics-once one of the more important topics in most universities - started to play a much less prominent role. Ethics has, however, always remained a topic of great importance and it has also had a tendency to pop up in times of trouble and disturbance when the wheels are not spinning as smoothly, i.e., when inequalities and income gaps increase or when the scientific and technical dream of constant progress no longer seems to make sense. Medical ethics is one case in point: Although developed already during the 18th and 19th century its relevance has steadily increased since the second half of the 20th century, in the wake of problematic medical experiments tainted by scientific hubris as well as a growing biotechnical development. Recently, and in the wake of climate change, it seems as if ethics have slowly come to the fore again on a more general level. In fact, it seems to be increasingly clear that technical solutions will never save us, nor can they help us build a sustainable society if we keep on living in unsustainable ways. Technologies (and here we include the built environment in all its guises) do not exist in a vacuum, but are put into play in contexts of social values, qualities, and norms which they both transform; and in turn are transformed by. But what does a contemporary ethical perspective on urban planning and design look like? Certainly it should not be developed along the nor- 
mative and sometimes dogmatic ways that we saw in the 17th century; rather the debate needs to be concerned with bringing in more voices and try to reckon with relevant actors into discussions around contemporary themes, such as spatial justice (Fainstein, 2010), the green imperative (Fox, 2000), diversity (Sennett, 2018), urban politics (Mostafavi, 2017), matters of concern (Puig de la Bellacasa, 2017), living in ruined landscapes (Tsing, 2015), etc. In fact, it seems increasingly clear that ethics must be expanded to include more actors than just humans (Haraway, 2016; Latour, 2018; Stengers, 2003; Yaneva \& Zaera-Polo, 2017), since they play a role and increasingly seem to suffer the effects of our actions. Urban materialities affect how we live our lives. If the roads are wide and comfortable we drive; if there is no green space available close by where we live, we might take the car to a park or to the forest. The built environment takes part in producing our actions, and as such it also takes part in the co-production of an ethic. In a similar way, our actions have their effects on non-humans: air and water get polluted; animals are made extinct; forests are burned down; etc.; effects that in turn affect human lives. Our everyday morale is thus never produced by us alone-our intentions are not formed outside the world but in the middle of it.

\section{Perspectives on Ethicality}

The goal of this thematic issue is to investigate the increasingly complex relation between built environment and everyday ethics. The issue presents ethical discussions and considerations in relation to the built environment, urban materialities, and the everyday. The range of questions tackled thus acknowledges some of the ethical perspectives that are explicitly, or implicitly, involved in the problems that now are facing the field of urban planning and design. At the core of these questions is a concern for everyday life, and the ways in which mundane activities depend on and in different ways relate to the built environment. Although this relation has been acknowledged in different contemporary designs, the problem, we think, has quite often been dealt with in an unsatisfactory way. In fact, certain choices and aspects of ordinary life seem to be increasingly made invisible by means of design (for example in so called smart city solutions), by designs favouring clarity over complexity (Sennett, 2018) or through strategies such as nudging (French, 2011). These approaches tend to frame certain aspects as more important or salient than others, potentially decreasing the affordances and diversity of our built environment. In contrast to this, several articles in this theme issue do actually point to an opposite need, i.e., the need to embrace transparency and complexity. The goal cannot be reached through simple cause-and-relation logics or one-for-all solutions. Choices and relations are becoming increasingly complex and this is something that needs to be made visible and transparent rather than simply black-boxed or manifest- ed as some technical machine, designed with a belief in that hardy modern myth that good deeds can be universal and set beyond a context or situation.

In this issue we present a series of articles on urban ethics that we think can be sorted under four different themes: a) new materialities; b) community building; c) planning for sustainability; and d) participation and communication. The first theme deals with the different ethical dilemmas and concerns that arise around new materialities (La Cecla \& Zanini, 2013) and addresses the changing role of street furniture in everyday life, the affordance of blue-green solutions, and the urban borders constituted by mental healthcare facilities.

In their article "Ontological Boundaries or Contextual Borders: The Urban Ethics of the Asylum," Ebba Högström and Chris Philo (2020) argue against "the asylum' as a neutral site in the city. Based on the case study of Gartnavel Royal Hospital in Glasgow, and through contacts with individuals that navigate its borders, they ask to what extent mental healthcare facilities are incorporated in the rest of the city. The authors interrogate if such institutions have become more integrated and on what ethical grounds urban planning treats the seemingly clear, but in a direct experience more porous, boundaries of mental healthcare facilities.

Johan Wirdelöv (2020), for his part, investigates how a "deceptively innocent" group of street furniture that keeps proliferating in our cities influence and encourage our behaviour in the city. Street furniture is reflected upon as artefacts that follow current trends in urban design, and support some events that are seen as sustainable, such as skateboard-friendly or solar-powered objects, while other events or individuals are instead seen as unwanted and excluded by hostile design. Through the suggestion of three furniture roles-carnivalesque street furniture that has temporal functions, behaviourist street furniture which engages in human public action, and cabinet-like street furniture which relocates other objects-Wirdelöv (2020) conceptualizes the material culture of street furniture for further investigations into the sociomaterial aspects of everyday life.

Misagh Mottaghi, Mattias Kärrholm and Catharina Sternudd (2020) inquire into the ethical consequences that blue-green solutions (BGS), managing stormwater, and climate change in situations of urban densification can have on everyday life. While urgent sustainability concerns are addressed with the introduction of BGS, these technical solutions present challenges in the form of new affordances that have an impact on everyday life in public space. Through the case study of Augustenborg in Malmö, Sweden, they exemplify how BGS tend to introduce a new kind of sensitivity and intensification of concerns and negotiations with significant social consequences.

The second theme revolves around community building, including both the forming of ethicalities in everyday communities and the growing need to facilitate for new communities or publics in an increasingly mobile society. 
This also involves a discussion of different strategies for designing such communities as well as some of the problems or particularities involved in their formation.

In their investigation of the everyday ethics and sociability of outdoor ice rinks in Canada, Mervyn Horgan, Saara Liinamaa, Amanda Dakin, Sofia Meligrana, and Xu Meng (2020) give us a rich picture of the social life of public ice rinks and the different interactions between strangers. They discuss how the production of an everyday ethics here, among other things, seems to be connected to personal materialities, spatially situated norms, carnivalesque moments, and flattened social hierarchies.

Shelly Cohen's and Yael Allweil's contribution (2020) explores dwellings for seniors who live with caretakers through the design of Tel Aviv Metropolis apartments in Israel. They make a plea for a non-ageist housing where not only families with children are considered in design but also the need to adapt the dwellings for caring in old age. The article includes a design proposal which suggests a division of seniors' apartments into a primary and secondary unit in order to better provide a spatial organization for shared residency.

Ida Sandström (2020) looks at two different design approaches to counter segregation in public space. She discusses two contemporary public space projects-Superkilen in Copenhagen, Denmark, and Jubileumsparken in Gothenburg, Sweden. These are taken as examples of how design is thought to help us learn to be affected (the focus of the Copenhagen case) and care (the focus of the Gothenburg case), thus forming very different kinds of ethics in relation to the forming of communities.

In "Coffeehouses (Re)Appropriated: Counterpublics and Cultural Resistance in Tabriz, Iran," Laleh Foroughanfar (2020) looks at how counterpublics and cultural resistance are formed in the traditional coffeehouses of Tabriz, Iran. Through an ethnographic study, she maps the mechanisms of everyday ethics and how resistance and security are produced through practices that stabilise identity, but that also involve a process of othering and the production of a mono-gendered social environment.

The third theme that we cover in this issue is the ethical stakes and dilemmas in relation to sustainable planning. How can we plan sustainable cities, and perhaps more importantly, what learnings can we draw from contemporary efforts made so far? Here, it is suggested that the supposedly good and inclusive, or seemingly objective and neutral solutions, that are advocated within in contemporary urban planning also need to be accompanied by continuous ethical deliberations.

In her article "Guilt-Tripping: On the Relation between Ethical Decisions, Climate Change and the Built Environment," Paulina Prieto de la Fuente (2020) discusses climate-related decision-making in everyday life and its relation to guilt and shame. Drawing from her empirical study of the growing suburb of Stångby, just outside Lund, Sweden, she notes how people's good intentions quite often are hard to follow in everyday life where the room to maneuver different demands and circumstances can often be limited. Everyday life always carries an element of creative togetherness, as inhabitants and their environment depend on each other. This co-existence and how it unfolds over time needs to be better understood and taken into account by planning.

Pernilla Hagbert's, Josefin Wangel's, and Loove Broms' (2020) article is a critical examination of how an eco-modern imaginary is reproduced in sustainable planning in Sweden. In their investigation, they show how a contemporary sustainable planning rather than challenging the predominant regimes sustains them and the authors argue for a more ethically engaged sustainable planning that critically challenges and discusses planning agendas in relation to relevant scales, the use of resources, and the production of subjectivities.

Sandra Kopljar (2020) partly connects to this argument as she digs deeper into the notion of scale. In relation to the supposedly sustainable urban development of Lund regarding the new large-scale science facilities MAX IV and European Spallation Source, she discusses how planning intentions might align with expected outcomes on one scale but not the other. These contradictions in planning interests cannot be resolved unless we start to lift the issue of scale into a discussion of urban planning ethics.

The fourth and final theme concerns justice and equality, and more specifically participation and design dialogues. In his article "Lack of Participatory Effort: On the Ethics of Communicating Urban Planning," Gunnar Sandin (2020) points to shortcomings in participatory planning processes regarding land-use where seemingly democratic processes are identified as lacking real influence because of a lack of communication. A need for such processes of communication to last for some time, and to be adapted to the conditions of those concerned, is vital. The especially problematic 'successive translational steps' and 'dialogic reciprocity' are found to constitute areas of potential development.

Barbara Roosen, Liesbeth Huybrechts, Oswald Devisch, and Pieter van den Broeck (2020), finally, explore 'dialectical design dialogues' as a method for engaging in ethics in urban planning contexts. The dialectic approach acknowledges contrasting ethical standpoints and investigates these through an atlas as a methodological tool in the case study of a residential neighbourhood in Genk, Belgium. In the collective production of the atlas both professionals and laymen develop possible future scenarios on the basis of competing ideas and where the technique itself, and the example of 'real-time' urban planning process, contributes to the advance of urban planning.

\section{Conclusions}

Together, the articles of this issue present different openings into urban ethics and suggest different themes and 
questions worthy of further interrogation. First of all, we have made it clear that new materialities and design solutions are always accompanied by new ethical issues and concerns. Two effects especially pointed to here is, for example, the ethical implications of densification (through the proliferation of street furniture on public places, or through the implementation of blue-green solutions in an existing park environment), and urban boundaries and borders (for example between the city and certain institutions or institutional areas). Secondly, we have highlighted different aspects involved in the design and ethics of community building. This included the discussion of the integration of different groups through design (both in residential spaces and public spaces) and the forming of ethics and its relation to both inclusion and othering (both in outdoor and indoor spaces). Thirdly, we have addressed the issue of sustainable planning by pointing to some of the shortcomings in contemporary efforts to account for scale relations, the production of different subjectivities, the use of resources in everyday life, as well as the problems of accounting for how the ongoing negotiations between people's everyday life and their environmental concerns are mediated through urban design. Finally, we have pointed to the need to further investigate communication, translation, and influence in participatory design processes. Taken together, we hope that this issue-by highlighting the ethicality in processes and relations of urban planning, design, and everyday life-can inspire further studies into the much needed field of investigation that is urban ethics.

\section{Acknowledgments}

This thematic issue has been supported by Formas through Project 2017-01943 "Urban design and everyday life choices: On the built environment as a coproducer of climate ethics."

\section{Conflict of Interests}

The authors declare no conflict of interests.

\section{References}

Cohen, S., \& Allweil, Y. (2020). Towards non-ageist housing and caring in old age. Urban Planning, 5(4), 155-170.

de la Fuente, P. P. (2020). Guilt-tripping: On the relation between ethical decisions, climate change and the built environment. Urban Planning, 5(4), 193-203.

Fainstein, S. (2010). The just city. Ithaca, NY: Cornell University Press.

Foroughanfar, L. (2020). Coffeehouses (re)appropriated: Counterpublics and cultural resistance in Tabriz, Iran.
Urban Planning, 5(4), 183-192.

Fox, W. (2000). Ethics and the built environment. London: Routledge.

French, J. (2011). Why nudging is not enough. Journal of Social Marketing, 1(2), 154-162.

Hagbert, P., Wangel, J., \& Broms, L. (2020). Exploring the potential for just urban transformations in light of eco-modernist imaginaries of sustainability. Urban Planning, 5(4), 204-216.

Haraway, D. J. (2016). Staying with the trouble: Making kin in the Chthulucene. Durham, NC: Duke University Press.

Högström, E., \& Philo, C. (2020). Ontological boundaries or contextual borders: The urban ethics of the asylum. Urban Planning, 5(4), 106-120.

Horgan, M., Liinamaa, S., Dakin, A., Meligrana, S., \& Meng, X. (2020). A shared everyday ethic of public sociability: Outdoor public ice rinks as spaces for encounter. Urban Planning, 5(4), 143-154.

Kopljar, S. (2020). Big science, ethics, and the scalar effects of urban planning. Urban Planning, 5(4), 217-226.

La Cecla, F., \& Zanini, P. (2013). The culture of ethics. Chicago, IL: Prickly Paradigm Press.

Latour, B. (2018). Down to Earth: Politics in the new climatic regime. Cambridge: Polity Press.

Mostafavi, M. (2017). Ethics of the urban. Zurich: Lars Müller.

Mottaghi, M., Kärrholm, M., \& Sternudd, C. (2020). Blue-green solutions and everyday ethicalities: Affordances and matters of concern in Augustenborg, Malmö. Urban Planning, 5(4), 132-142.

Puig de la Bellacasa, P. (2017). Matters of care: Speculative ethics in more than human worlds. Minneapolis, $\mathrm{MN}$ : University of Minnesota Press.

Roosen, B., Huybrechts, L., Devisch, O., \& van den Broeck, P. (2020). Dialectical design dialogues: Negotiating ethics in participatory planning by building a critical design atlas. Urban Planning, 5(4), 238-251.

Sandin, G. (2020). Lack of participatory effort: On the ethics of communicating urban planning. Urban Planning, 5(4), 227-237.

Sandström, I. (2020). Learning to care, learning to be affected: Two public spaces designed to counter segregation. Urban Planning, 5(4), 171-182.

Sennett, R. (2018). Building and dwelling: Ethics for the city. London: Allen Lane.

Stengers, I. (2003). Cosmopolitics I-II. Minneapolis, MN: University of Minnesota Press.

Wirdelöv, J. (2020). The trash bin on stage: On the sociomaterial roles of street furniture. Urban Planning, 5(4), 121-131.

Yaneva, A., \& Zaera-Polo, A. (2017). What is cosmopolitical design? Design, nature and the built environment. Abingdon: Taylor \& Francis. 


\section{COGITATIO}

\section{About the Authors}

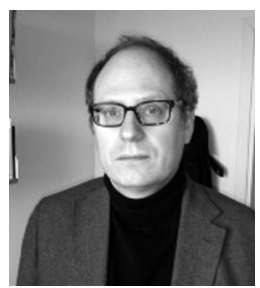

Mattias Kärrholm is Professor in Architectural Theory at Lund University, Sweden. His research deals with territoriality, public space, building types, space and culture, and everyday life. He has written the books Retailising Space (Ashgate, 2012) and, with Andrea Mubi Brighenti, Animated Lands, Studies in Territoriology (Nebraska University Press, 2020). He has also edited the volumes Urban Squares (Nordic Academic Press, 2015) and Urban Walls (with Andrea Mubi Brighenti, Routledge 2019).

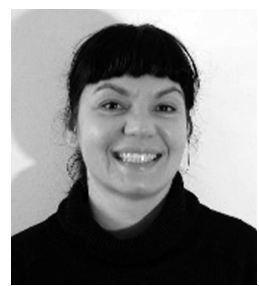

Sandra Kopljar is an Architect and Associate Senior Lecturer at the Department of Architecture and Built Environment, LTH-Lund University. Kopljar's research interest revolves around urban development and design processes connected to design professionals' methodology and pedagogy. These themes are investigated in relation to design, in artistic research that explores architecture methodology, and in research about the handling of everyday actions and strategies in relation to the built environment. 